\title{
Раскрытие информации об интеллектуальном капитале и его влияние на стоимость компаний на развивающихся рынках капитала
}

\author{
Байбурина Э.Р. ${ }^{27}$, Гребцова Е.Г. ${ }^{28}$
}

\begin{abstract}
Развитие информащионных технологий, рост значимости знаний, принципиальная важность инноваций для получения конкурентного преимущества ставят новые непростые задачи перед современными компаниями во многих аспектах их деятельности. Одна из таких задач - адекватное донесение информации о себе внешним и внутренним заинтересованным лицам, или стейкхолдерам, $\kappa$ которым относится менеджмент компании, ее работники, инвесторы, государство, кредитные организации и прочие. Отметим, что раскрытие информации об интеллектуальном капитале особенно актуально на развиваюшихся рынках из-за их неэффективности, которая часто приводит $к$ неадекватной оченке компании стейкхолдерами. В рамках данной работь будет представлена нефинансовая оценка интеллектуального капитала кумулятивным методом, представляющая собой составление индекса раскрытия информации об интеллектуальном капитале. Непосредственный интерес представляет переход на принципиально иной уровень анализ раскрытия информации об интеллектуальном капитале и включение этого показателя в регрессионные модели, с тем чтобы оценить систематический вклад интеллектуального капитала в создание стоимости компании. Работа организована следующим образом: в первой части приведен краткий обзор работ, посвященных определению и классификации интеллектуального капитала, его оценке и влиянию на стоимость компаний. Во второй части приводится модель оценки влияния раскрытия информации об интеллектуальном капитале на стоимость компании с помощью индекса. Наконеи, в заключение работы приводятся основные результаты и выводы из проведенного исследования и даются рекомендации по дальнейшему развитию тематики. Проведенное исследование позволяет получить обобщенную картину раскрытия информации об интеллектуальном капитале в компаниях развивающихся стран (Бразилии, России, Китая, Южной Африки), а также показывает, что раскрытие подобной информаџии способствует росту стоимости компании, позволяя стейкхолдерам оценивать ее более адекватно. В статье показань результаты проекта «Исследования корпоративных финансовых решений компаний России и других стран с развивающимися рынками капитала в условиях глобальной трансформаџии рынков капитала и становления экономики инновационного типа» выполненного в рамках программы фундаментальных исследований Национального исследовательского университета «Высшей школь экономики» в 2012 году.
\end{abstract}

JEL: G32, G34, G35, L21, L26, M14, M51, M52, O31, O32, O34

Ключевые слова: интеллектуальный капитал, индекс раскрытия информации, развивающиеся рынки капитала, БРИКС, стоимость компании

\footnotetext{
${ }^{27}$ Преподаватель кафедры экономики и финансов фирмы, департамента финансов, факультета экономики; сотрудник Лаборатории корпоративных финансов Национального исследовательского университета «Высшей школы экономики».

${ }^{28}$ Студентка магистратуры кафедры экономики и финансов фирмы, департамента финансов, факультета экономики; стажер Лаборатории корпоративных финансов Национального исследовательского университета «Высшей школы экономики».
} 


\section{Введение}

Создание стоимости компании с помощью интеллектуального капитала - одна из ключевых задач экономики, основанной на знаниях. Периодическая оценка интеллектуального капитала, проводимая в интересах ключевых стейкхолдеров компании, позволяет определить наиболее динамично развивающиеся его компоненты, а также усилить поддержку тех компонентов, которые не до конца раскрыли свой потенциал роста. Это в свою очередь стимулирует менеджмент принимать решения, направленные на развитие, что формирует базис для построения устойчивой бизнес-модели. Одновременно с этим существенным обеспечением устойчивого роста является своевременное раскрытие информации о существенных компонентах интеллектуального капитала.

Стандартные отчетные формы более не способны решить эту проблему, прежде всего из-за того, что драйверами роста стоимости компаний первостепенной важности становятся ее интеллектуальные ресурсы. Учет интеллектуальных ресурсов необходим для более адекватной оценки компании. Кроме того, определение типа интеллектуального капитала, способствующего в наибольшей мере созданию стоимости и умение оценить его, позволило бы более эффективно управлять компанией. Таким образом, вопросы определения и измерения интеллектуального капитала приобретают первостепенную значимость в современной экономике.

Отметим, что раскрытие информации об интеллектуальном капитале (далее - ИК) особенно актуально на развивающихся рынках из-за их неэффективности, что приводит к неадекватной оценке компании стейкхолдерами.

В рамках данной работы будет представлена нефинансовая оценка интеллектуального капитала кумулятивным методом в классификации Свейби, представляющая собой составление индекса раскрытия информации об интеллектуальном капитале. Несмотря на распространенность исследований, в которых интеллектуальный капитал компании оценивается аналогичным образом, многие из них носят лишь описательный характер. То есть, предполагают составление индекса по методологии различного уровня сложности и получения вывода относительно уровня раскрытия в том или ином периоде в целом и по компонентам ИК (Abeysekera, Guthrie, 2005; Kamath, 2008; Goh, Lim, 2004), в некоторых случаях - с применением корреляционного анализа для уровня раскрытия и капитализации компании. Недостаток подобных исследований состоит в анализе небольших промежутков времени (1-2 года), тогда как формирование интеллектуального капитала - достаточно длительный процесс. На следующем уровне анализа применяется непараметрическое тестирование (тесты Вилкоксона, Фридмана) гипотез о связи индекса раскрытия информации об ИК и таких показателей, как размер компании, отрасль темпы роста и др. (Branco et al., 2010).

Непосредственный интерес представляет переход на принципиально иной уровень анализа раскрытия информации об интеллектуальном капитале и включение этого показателя в регрессионные модели, с тем, чтобы оценить систематический вклад интеллектуального капитала в создание стоимости компании. Таким образом, основная цель исследования - провести анализ раскрытия информации об интеллектуальном капитале и его влияние на стоимость компаний на развивающихся рынках капитала. Для реализации основной цели исследования необходимо разбить ее на несколько вспомогательных:

- провести анализ практик раскрытия информации об интеллектуальном капитале компаниями крупнейших развивающихся стран;

- рассмотреть методологию составления индексов раскрытия информации об интеллектуальном капитале;

- провести анализ влияния раскрытия информации об интеллектуальном капитале на стоимость компании.

Соответственно, для реализации цели необходимо решить следующие задачи: 
- рассмотреть определения и классификации интеллектуального капитала и выбрать наиболее удовлетворительные с точки зрения целей исследования;

- обосновать необходимость раскрытия информации об интеллектуальном капитале;

- проанализировать исследования, посвященные оценке интеллектуального капитала кумулятивным методом;

- провести оценку практик раскрытия информации компаний крупнейших развивающихся стран на основании выбранной методологии;

- оценить влияние раскрытия информации об интеллектуальном капитале на стоимость компании;

- сформировать общие выводы и рекомендации по дальнейшему развитию тематики.

Объектом исследования является раскрытие информации котирующимися компаниями крупнейших развивающихся стран.

Предмет исследования - это информация об ИК и ее отображение в тех или иных источниках информации.

Для проведения исследования необходимы данные из финансовой отчетности компаний, которые будут получены из базы данных Bloomberg. Для оценки практик раскрытия информации будут использоваться годовые отчеты компаний, представленные на их официальных веб-сайтах.

Исходя из поставленных основных цели и задач, работа организована следующим образом: в первой части приведен краткий обзор работ, посвященных определению и классификации ИК, его оценке кумулятивным методом и влиянию на стоимость компаний. Во второй части приводится модель оценки влияния индекса раскрытия информации об ИК на стоимость компании. Наконец, в заключение работы приводятся основные результаты и выводы из проведенного исследования и даются рекомендации по дальнейшему развитию тематики.

\section{1. Понятие, классификации и измерение интеллектуального капитала}

\section{1. Понятие интеллектуального капитала}

Интеллектуальный капитал, его классификация и методы учета попали под пристальное внимание ученых в 80-е годы прошлого века, когда очевидным стало существование разрыва между рыночной стоимостью компаний и их балансовой стоимостью (Chiung, Ming, 2005). Причины этого несоответствия требовали объяснения. За прошедшие годы было приведено множество различных определений ИК. При формулировании определений авторы используют несколько уровней агрегирования, начиная с общего понятия, такого как «нематериальные активы» (Puntillo, 2009) или «материал» (Klein, Prusak, 1994). Далее, как правило, приводятся непосредственно компоненты интеллектуального капитала, выделяемые тем или иным автором: технологии, бренд, клиентская информация, репутация, корпоративная культура, знания работников, опыт, интеллектуальная собственность и др. Наконец, большинство авторов отмечают в своих определениях существенную значимость интеллектуального капитала с точки зрения создания конкурентного преимущества компании (Bayburina, Golovko, 2009: Puntillo, 2009; Bontis, 2003), в том числе в форме возможности производства товаров с высокой добавленной стоимостью (Klein, Prusak, 1994). Также в определениях некоторых авторов интеллектуальный капитал рассматривается как непосредственный драйвер создания стоимости компании.

Таким образом, каждый автор дает свое понятие интеллектуального капитала, содержание которого варьируется, в частности, в зависимости от направления исследований, проводимых автором, хотя многие выделяют важность ИК для создания стоимости. Аналогичная ситуация складывается и в области структурирования интеллектуального капитала: существует множество различных классификаций ИК. Традиционно выделяется три основных компонента: человеческий, клиентский и структурный капитал (Brennan, Connell, 2000; Petty, Cauganesan, 2005). Исследователи Родов и Лелиаэрт (Rodov, Leliaert, 
2002) также используют традиционную классификацию, однако при этом подчеркивают значимость взаимодействия элементов интеллектуального капитала с последующим образованием новых элементов (схема 1).

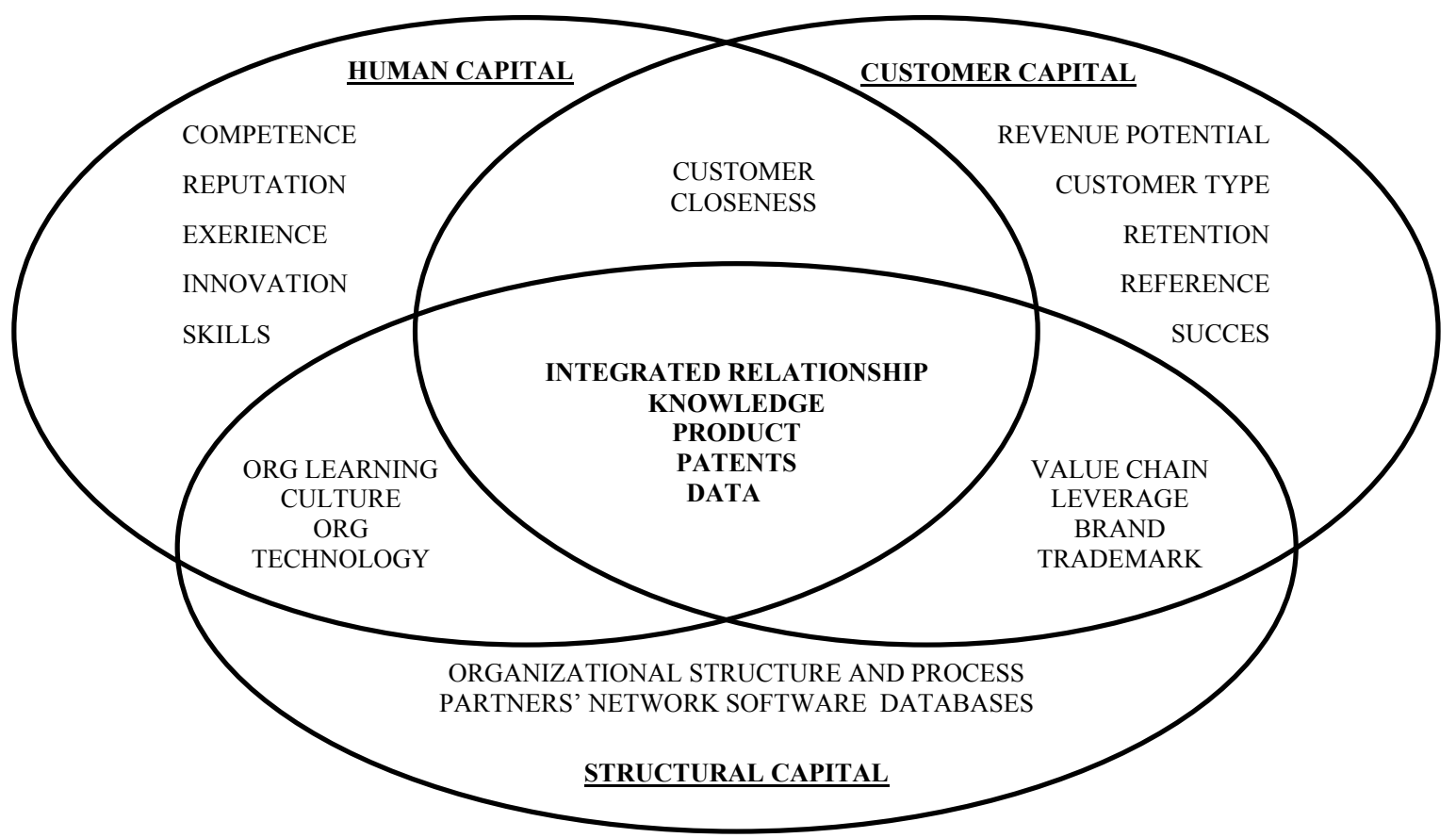
2002)

Схема 1. Структурирование компонентов интеллектуального капитала (Rodov, Leliaert,

Отмечается существенность взаимосвязи различных элементов ИК и в другой ключевой работе в рассматриваемой тематике, несмотря на то что авторы (Kaplan, Norton, 1992) предлагают несколько иную классификацию самих компонентов (схема 2).

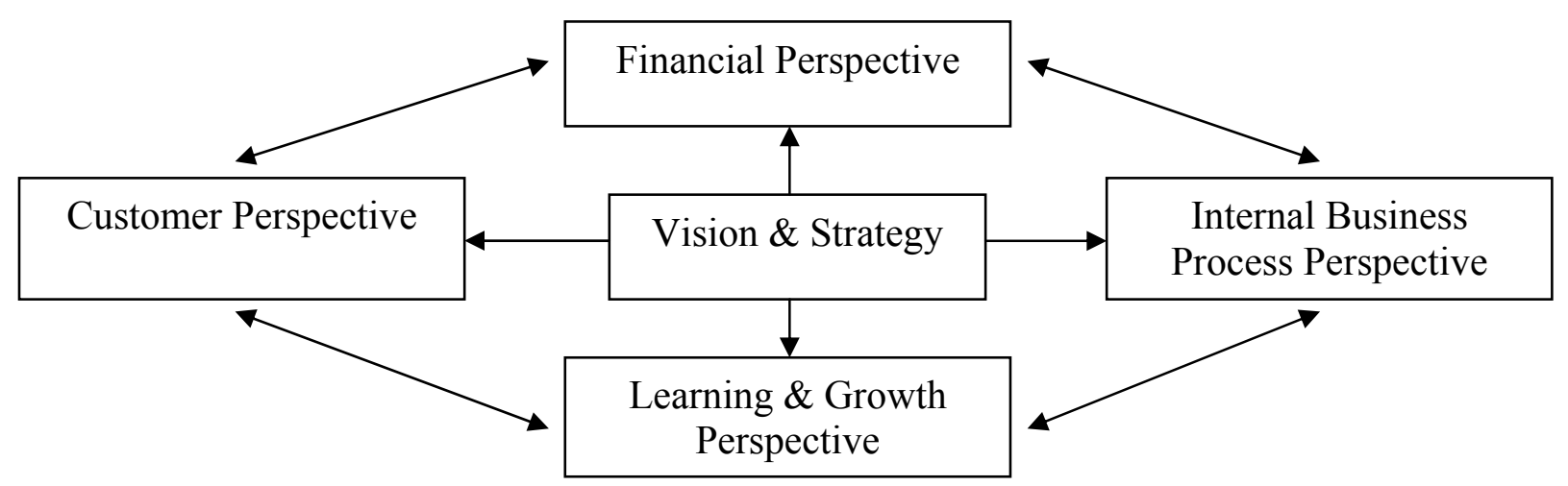

Схема 2. Структурирование компонентов интеллектуального капитала в системе сбалансированных показателей (Kaplan, Norton, 1992)

В системе сбалансированных показателей, созданной Каплан и Нортон (Kaplan, Norton, 1992), результативность деятельности компании определяется следующими основными направлениями: финансовым, клиентским, внутренними бизнес-процессами, а также знаниями и ростом. Еще одна ключевая схема структурирования интеллектуального капитала разработана другими исследователями (Edvinsson, Malone, 1997) и отличается от предыдущих, в частности, выделением наибольшего числа элементов (схема 3). 


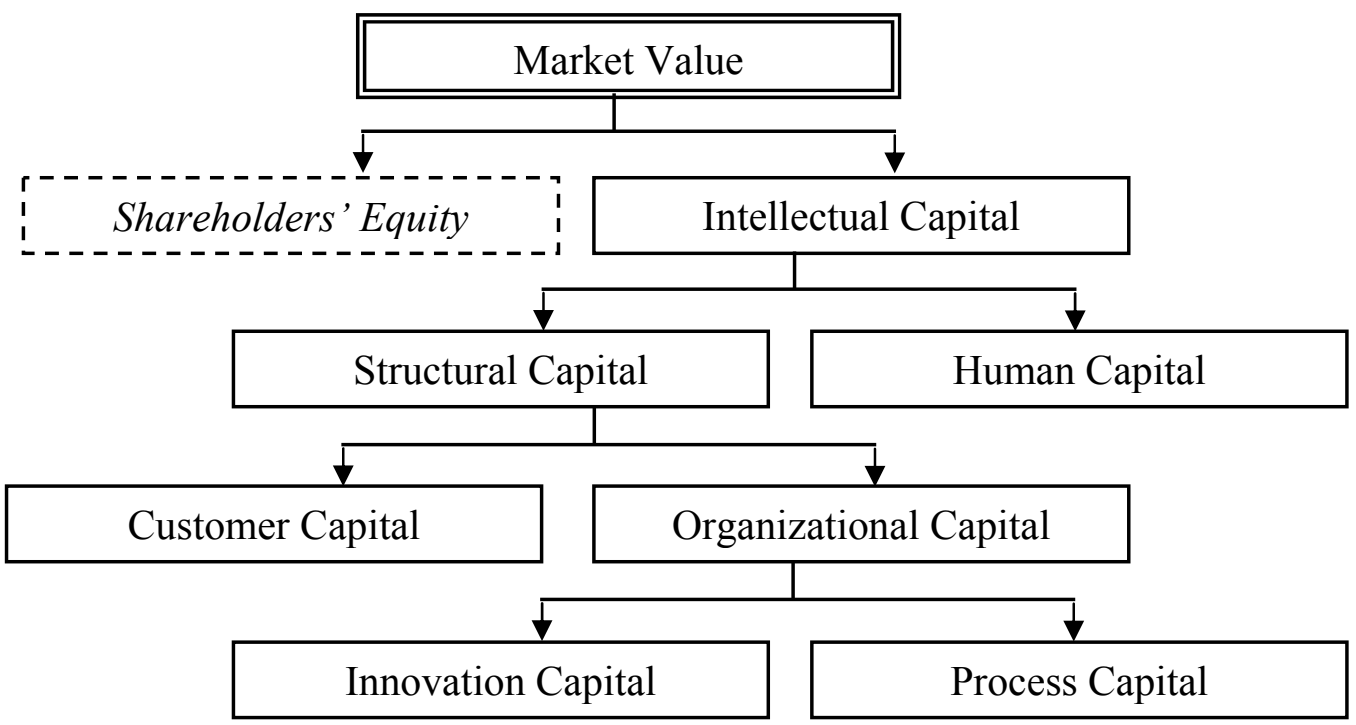

Схема 3. Структурирование компонентов интеллектуального капитала в работе (Edvinsson, Malone, 1997)

При этом элементы ИК выделяются в несколько этапов. Компоненты первого уровня это структурный и человеческий капитал. Структурный капитал в свою очередь делится на клиентский и организационный. А в рамках последнего выделяются инновационный и процессный капитал.

Отметим, что в более поздних исследованиях авторы, как правило, используют одну из схем структурирования интеллектуального капитала в первоначальном или модифицированном, в зависимости от целей исследования, виде.

За десятилетия развития концепций интеллектуального капитала помимо определений и классификаций была разработана масса способов его оценки. Так, по данным Sveiby Knowledge Associates ${ }^{29}$, существует 42 метода измерения интеллектуального капитала, которые делятся по уровням (организационный и с определением компонентов ИК), по типу оценки (денежная и неденежная). В целом их можно разделить на четыре основные группы: методы прямого измерения интеллектуального капитала, методы рыночной капитализации, методы отдачи на активы, кумулятивные методы. Стоит отметить, что на сегодняшний день целесообразность использования отдельно взятого метода оценки - дискуссионный вопрос (табл. А в приложении).

\section{2. Мотивы раскрытия информации об интеллектуальном капитале}

Несмотря на то что раскрытие информации об ИК не является обязательным, в частности, в силу высокой специфичности данного ресурса и затруднительности создания стандартов отчетов, компании раскрывают информацию об интеллектуальном капитале, и уровень раскрытия подобной информации увеличивается из года в год, о чем свидетельствуют различные исследования, проведенные, в том числе и на развивающихся рынках капитала. Таким образом, становится очевидным, что раскрытие информации об ИК позволяет компании получить некие выгоды, превышающие издержки раскрытия информации сверх требуемой. В современных исследованиях выделяется четыре основные теории, позволяющие объяснить причины, побуждающие компании добровольно раскрывать информацию об интеллектуальном капитале (An et al., 2011; Miller, Whiting, 2008): агентская теория, теория стейкхолдеров, сигнальная теория, теория легитимности (табл. $B$ в приложении).

Указанные теории во многом перекликаются друг с другом, поэтому на их основе можно выделить три основных мотива добровольного раскрытия информации об ИК (схема 4):

\footnotetext{
${ }^{29}$ www.sveiby.com
} 


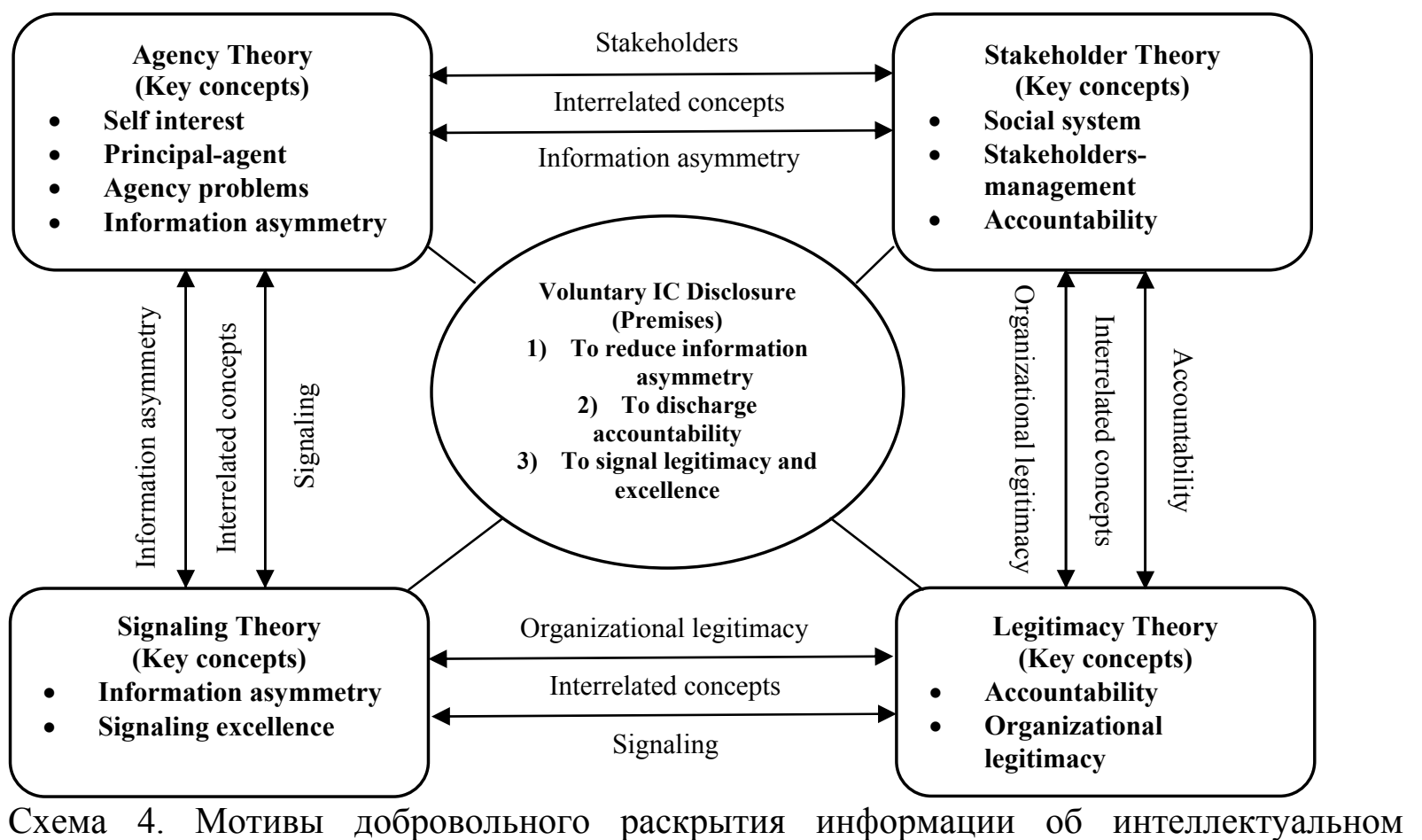

капитале (An et al., 2011)

- Сокращение асимметрии информации между менеджментом организации и различными стейкхолдерами компании.

- Выполнение обязательств перед стейкхолдерами.

- Подача сигнала о легитимности и преимуществах компании.

\section{3. Исследования влияния раскрытия информации об интеллектуальном капитале на стоимость компании}

Как отмечается в исследовании Анама и других авторов Энем (Anam et al., 2011), количество исследований, в которых непосредственно оценивается влияние интеллектуального капитала на стоимость компании, невелико. Так, указанное исследование является первой работой для компаний Малайзии, которая носит не только описательный характер. На основе регрессионного анализа, авторы получают, что уровень раскрытия информации в годовых отчетах 70 компаний Малайзии в 2002 и 2006 годах имеет значимое положительное влияние на рыночную капитализацию. Аналогичный результат получен для раскрытия информации в годовых отчетах компаний США (Abdolmohammadi, 2005).В коллективном исследовании Оренса (Orens et al, 2009) анализируется влияние раскрытия информации об ИК на интернет-сайтах компаний Бельгии, Франции, Германии и Нидерландов на капитализацию компании и показывается положительная связь этих показателей. Исследование Цитрона и других авторов (Citron et al., 2005) посвящено соответствующему анализу раскрытия информации об ИК на интернет-сайтах компаний Великобритании и также позволяет заключить, что раскрытие информации об ИК приводит к переоценке акций компании в сторону повышения их стоимости. Схожий результат получен и для компаний такой развивающейся страны, как Шри-Ланка (Abeysekera, Guthrie, 2005). В рассмотренных исследованиях авторы в большинстве случаев анализируют линейные модели зависимости капитализации компании от контрольных переменных (размер компании, рычаг, чистая прибыль) и индекса раскрытия информации об интеллектуальном капитале. Основным результатом подобных исследований является подтверждение значимости и положительности влияния интеллектуального капитала на стоимость компании. При этом особое внимание авторы уделяют методологии составления индекса раскрытия информации об интеллектуальном капитале, которая будет рассмотрен ниже. 


\section{4. Принципы контент-анализа в исследованиях раскрытия информации об интеллектуальном капитале}

Существенное значение с точки зрения реализации контент-анализа и формирования основной объясняющей переменной имеют несколько параметров:

1. Метод анализа. В большинстве исследований, в которых применяется контентанализ, данный метод реализуется «вручную», а не с помощью компьютерных программ. Последние позволяют существенно ускорить процесс анализа, но их применение может привести к получению неточных оценок из-за неучета контекста. Возможно и комбинирование «ручного» и автоматического анализа, которое применяется и в данном исследовании.

2. Источник информации. В качестве источника могут рассматриваться годовые отчеты компаний или их разделы; иные отчеты, предоставляемые компаниями; официальные интернет-сайты компаний; отчеты аналитиков; новостные ленты и др. Преимуществом годовых отчетов является то, что они проходят аудиторскую проверку, соответственно, информацию, представленную в них, можно считать надежной (Abeysekera, Guthrie, 2005). Нельзя не отметить и тот факт, что годовые отчеты являются доступным источником информации даже для компаний в развивающихся странах, что и обосновывает выбор именно их для анализа.

3. Базовая единица анализа. Под базовой единицей анализа подразумевается определенная часть выбранного источника информации, которая может быть отнесена к тому или иному элементу интеллектуального капитала и несет в себе определенную значимую информацию (иначе - текстовая единица) (Abhayawansa, 2011). В качестве базовой единицы может рассматриваться слово, словосочетание, предложение, абзац, страница или текст целиком. Для компьютерного контент-анализа наиболее удобно использовать слова или словосочетания, поскольку их поиск легкоосуществим. Однако учет всех найденных для той или иной категории слов и словосочетаний без рассмотрения контекста может привести к смещению оценок, поэтому необходимо дополнительно анализировать предложения, в которых найдены базовые единицы.

4. Учет величины раскрытия информации. Количество раскрываемой информации может учитываться двумя способами. В рамках первого отмечается только наличие или отсутствие той или иной информации. Согласно второму подходу, необходимо учитывать и значимость информации, что может осуществляться несколькими методами:

- расчет части страницы, занимаемой релевантным раскрытием информации;

- расчет количества соответствующих слов, словосочетаний, предложений и проч.;

- расчет количества случаев появления той или иной темы (Abhayawansa, 2011).

5. Классификация компонентов интеллектуального капитала. Традиционно исследователи выделяют, следуя работе (Sveiby, 1997), три категории интеллектуального капитала: внешний, внутренний и человеческий, разбивая каждый компонент на несколько подкатегорий. Достаточно часто в исследованиях рассматривается 24 фразы для поиска (Guthrie, Petty, 2000, Bozzolan et al., 2006; Guthrie et al., 2006; Miller, Whiting, 2008, Branco et al., 2010). Также возможен расширенный список из 39 элементов (Bontis, 2003), 78 (Bukh, 2002).

6. Учет временной структуры информации. В некоторых исследованиях (Abhayawansa, 2011) авторы учитывают то, относится ли раскрываемая информация к прошлому, будущему или настоящему. Раскрытие информации, относящейся к будущему, показывает, как компоненты интеллектуального капитала способствуют созданию стоимости компании.

7. Характеристика раскрываемой информащии.

По типу:

- качественная;

- количественная (не финансовая);

- $\quad$ количественная (финансовая); 
- визуальная.

По характеру:

- $\quad$ положительная;

- отрицательная;

- нейтральная.

8. Итоговый показатель. В зависимости от сложности проводимого анализа итоговый показатель может представлять собой частоту упоминаний той или иной фразы или индекс, учитывающий характер раскрытия.

9. Обеспечение надежности (точности, воспроизводимости и стабильности) результатов раскрытия и интерпретации.

\section{2. Эмпирическое моделирование: оценка влияния раскрытия информации об интеллектуальном капитале на стоимость компании}

Целью данной части исследования является анализ влияния раскрытия информации об интеллектуальном капитале на стоимость компании с помощью индекса в соответствующей регрессионной модели на панельных данных. Основная гипотеза состоит в том, что раскрытие информации об интеллектуальном капитале и его компонентах положительно влияет на капитализацию компании.

\section{1. Выборка}

В данном исследовании проводится анализ годовых отчетов котируемых нефинансовых компаний стран БРИКС ${ }^{30}$.

Источником информации стала база данных Bloomberg и официальные веб-сайты компаний. Были приняты следующие критерии отбора компаний:

- Капитализация компании в 2011 году составляет более \$20 млн.

- Компания относится к любым отраслям, кроме финансов.

- Имеется информация о торгах и котировках акций на период с 2005 по 2010 год.

- Компания представляет отчетность с 2005 по 2010 год, в соответствии с МСФО, что необходимо для обеспечения сопоставимости балансовых показателей, используемых при моделировании.

- Компания имеет корпоративный веб-сайт, доступный на английском языке, поскольку именно он был источником отчетов компаний. На корпоративном сайте размещены годовые отчеты компании на английском языке.

- Годовые отчеты представляются в формате .pdf, что позволяет скачать отчеты и анализировать их с помощью соответствующего программного обеспечения. Некоторые компании, в частности из Бразилии, представляют годовые отчеты только в онлайн-версии, без возможности скачивания, что делает анализ невозможным.

- Годовые отчеты представляются за календарный год. Данный критерий был применен для обеспечения сопоставимости результатов анализа по разным странам и возможности их совместного анализа. Таким образом, компании Индии были исключены из итоговой выборки, так как они представляют годовые отчеты за финансовый год, заканчивающийся 31 марта. В выборке по Индии были представлены и компании, представляющие годовые отчеты за календарный год, что соответствует требованиям, сформулированным в данном исследовании. Однако это были дочерние компании крупных европейских предприятий, поэтому было решено, что они не могут отразить реальные практики представления отчетности индийских компаний. Схожая ситуация сложилась и со многими компаниями из ЮАР.

В результате применения всех вышеуказанных критериев была сформирована выборка из 38 компаний развивающихся стран (Бразилии, России, Китая, Южной Африки). Заметим,

\footnotetext{
${ }^{30}$ Бразилия, Россия, Индия, Китай, Южная Африка - начальные буквы названий стран образуют аббревиатуру БРИКС «С»-от англ. «S»-«South Africa».
} 
что анализируются компании из восьми отраслей за шесть лет - с 2005 по 2010 год (таким образом, рассматриваются 228 годовых отчетов):

- 13 компаний из Бразилии;

- 5 компаний из ЮАР;

- 15 компаний из Китая;

- 5 компаний из РФ.

На рисунке представлена структура рассматриваемой выборки по отраслям.

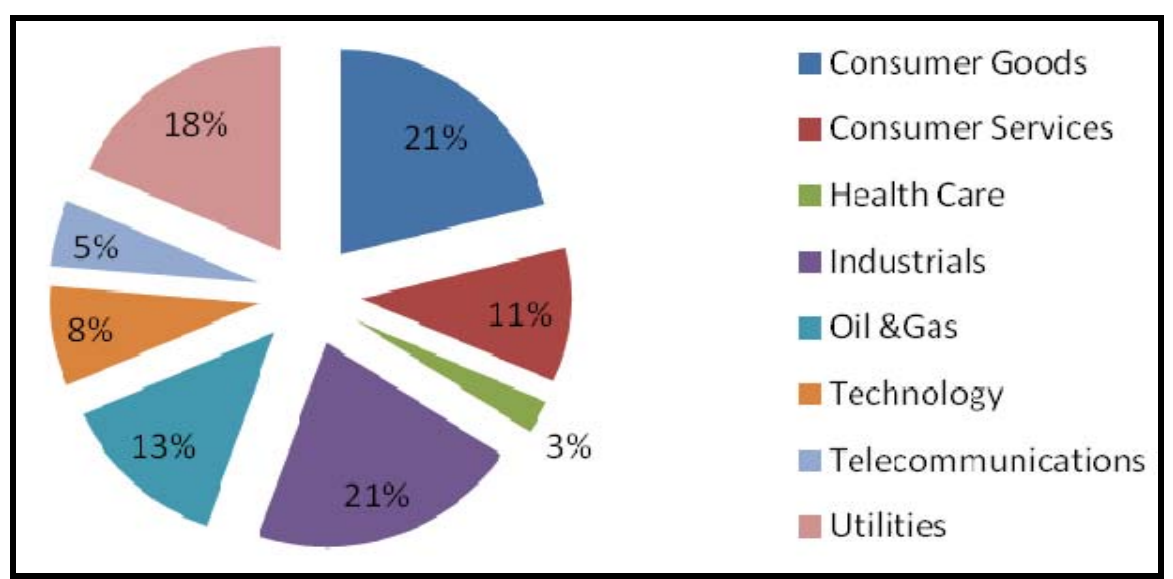

Рисунок 1. Структура выборки компаний развивающихся стран (Бразилия, Россия, Китай, Южная Африка) по отраслям

В качестве основного метода анализа уровня раскрытия информации об интеллектуальном капитале был выбран метод контент-анализа.

В данной работе был применен компьютеризированный анализ. Он осуществлялся с помощью программы PDF-XChange viewer, что позволило в относительно короткие сроки охватить достаточно большой объем информации. Кроме того, применение программы позволяет достичь большей надежности и объективности по сравнению с «ручным» анализом (Oliveras, 2008).

Отчеты каждой из 38 компаний были проверены на наличие словосочетаний, относящихся к интеллектуальному капиталу, которые приведены в приложении 2. Каждое словосочетание или текстовая единица анализировалось на предмет соответствия определенной категории интеллектуального капитала. Таким образом, производились корректировки в рамках предложения на выражения, не несущие должной смысловой нагрузки.

Словосочетания, используемые в данной работе, структурированы в три категории интеллектуального капитала:

- внутренний капитал;

- внешний капитал;

- человеческий капитал.

Выбор именно такого индекса обусловлен успешностью его применения в других исследованиях (Guthrie et al., 2006; Miller, Whiting, 2008).

К внутреннему капиталу относятся «знания, применяемые в организационных структурах и процессах» (Branco et al., 2010), он включает патенты, торговые марки, информационные системы и прочие показатели, связанные с ежедневной работой компании. К внешнему капиталу относятся взаимодействия с внешними стейкхолдерами, то есть клиентами, поставщиками, а также бренд, репутация (Branco et al., 2010). Наконец, к человеческому капиталу авторы (Petty, Cuganesan, 2005) относят «навыки и компетенции, тренинги и образование, опыт и ценностные характеристики работников компании» (Branco et al., 2010).

Также был разработан список терминов, относящихся к каждой из категорий 
интеллектуального капитала. Всего было выбрано 16 словосочетаний, относящихся к внутреннему капиталу, 13 - к внешнему капиталу и 16 показателей для человеческого капитала (табл. 1).

Таблица 1

Словосочетания, используемые при составлении индекса раскрытия информации об интеллектуальном капитале

\begin{tabular}{|l|l|l|}
\hline Internal capital & External capital & Human capital \\
\hline patent & customer loyalty & human capital \\
intellectual property & brand & knowledge \\
work processes & consumer & know-how \\
copyrights & customer & training \\
management philosophy & distribution channel & employee \\
structural capital & business collaboration & employee expertise \\
corporate culture & licensing agreement & employee knowledge \\
management processes & certification & entrepreneurial spirit \\
information system & favourable contract & expert \\
financial relation & franchising/franchise & talent \\
knowledge management & awards & experience \\
trademarks & company reputation & human resources \\
vision & & employee loyalty \\
mission & & teamwork \\
code of conduct & & merit \\
code of ethics & & team \\
\hline
\end{tabular}

Итоговые фразы поиска были подобраны на основе практических и теоретических работ по созданию индекса раскрытия информации, таких как исследования (Branco et al., 2010; Husin et al., 2012).

\section{2. Базовая эконометрическая модель} 2011):

Базовая модель может быть формально представлена следующим образом (Anam et al.,

$$
M C_{i t}=\alpha+X_{i t} \beta+Y_{i t} \gamma+\varepsilon_{i t},
$$

где $M C_{i t}$ - рыночная капитализация $i$-й компании в период времени $t, X$ - вектор показателей индекса раскрытия информации об интеллектуальном капитале $i$-й компании в период времени $t, Y$ - матрица показателей контрольных переменных $i$-й компании в период времени $t, \varepsilon_{i t}-$ независимо и одинаково распределенные статистические ошибки.

Далее рассмотрим контрольные переменные модели (табл. 2).

Таблица 2

Контрольные переменные модели

\begin{tabular}{|l|l|}
\hline$\Delta B V(\$)$ & $\begin{array}{l}\text { Разница балансовой стоимости активов и обязательств компании на } \\
\text { конец бухгалтерского года (Abdolmohammadi, 2005) }\end{array}$ \\
\hline NI (\$) & $\begin{array}{l}\text { Чистая прибыль на конец бухгалтерского года (Citron et al., 2005; } \\
\text { Orens et al., 2009) }\end{array}$ \\
\hline Size (\$) & $\begin{array}{l}\text { Размер компании, как величина активов на конец бухгалтерского } \\
\text { года (Beaulieu et al., 2002; Bozzolan et al., 2006) }\end{array}$ \\
\hline Leverage & $\begin{array}{l}\text { Отношение обязательств к собственному капиталу компании } \\
\text { (Williams, Nauman 2011) }\end{array}$ \\
\hline Industry & Дамми - переменная, указывающая на принадлежность компании к \\
\hline
\end{tabular}




\begin{tabular}{|l|l|}
\hline & отрасли \\
\hline Time & Дамми-переменная года \\
\hline Country & $\begin{array}{l}\text { Дамми - переменная, указывающая на принадлежность компании к } \\
\text { стране }\end{array}$ \\
\hline
\end{tabular}

Отметим, что финансовые переменные были нормализованы с помощью логарифмирования для сокращения разброса значений по сравнению с ключевыми переменными модели. Также, поскольку количество компаний из каждой страны невелико, решено было отказаться от введения в модель дамми-переменных стран. Аналогичное решение было принято относительно переменных отрасли. Временные дамми-переменные были структурированы в две группы. Первая из них объединяет три докризисных года (2005-2007), вторая - кризисный и посткризисный периоды (2008-2010).

Наконец, непосредственный интерес с точки зрения исследования представляет следующая переменная, включенная в модель также в виде логарифма:

- ICD index (Intellectual Capital disclosure index) - индекс раскрытия информации об интеллектуальном капитале.

В таблице 3 приведены индексы раскрытия информации об интеллектуальном капитале и его компонентах по годам по всем компаниям. Как видно, наименее раскрываемой категорией является структурный (внутренний) капитал, наиболее раскрываемой человеческий капитал. При этом наблюдается рост раскрытия информации из года в год. Результат относительно внутреннего капитала был получен и в других исследованиях (Abeysekera, Guthrie, 2005;Branco et al., 2010).

Ограниченный уровень раскрытия информации об этом типе капитала может частично объясняться желанием сохранить конкурентные преимущества от возможностей копирования. Относительно других типов капитала результаты исследований расходятся.

Таблица 3

Общий индекс раскрытия информации об интеллектуальном капитале

\begin{tabular}{|c|c|c|c|c|c|c|}
\hline Disclosure & $\mathbf{2 0 0 5}$ & $\mathbf{2 0 0 6}$ & $\mathbf{2 0 0 7}$ & $\mathbf{2 0 0 8}$ & $\mathbf{2 0 0 9}$ & $\mathbf{2 0 1 0}$ \\
\hline Internal capital & 457 & 457 & 424 & 509 & 556 & 646 \\
\hline External Capital & 2598 & 2336 & 2564 & 2778 & 2993 & 3323 \\
\hline Human Capital & 3056 & 2792 & 3148 & 3264 & 3555 & 3741 \\
\hline Total Intellectual Capital & 6111 & 5585 & 6136 & 6551 & 7104 & 7710 \\
\hline
\end{tabular}

\section{3. Тестирование модели}

При предварительном анализе данных была проведена их проверка на нормальность с помощью Skewness-Kurtosis test.

В процессе исследования было построено несколько сквозных» регрессионных моделей с помощью метода МНК, для каждой из которых были проведены тесты на мультиколлинеарность и гетероскедастичность. В итоговых моделях значение коэффициентов VIF не превышает 5. Тесты на гетероскедастичность позволили сделать вывод о ее отсутствии на $1 \%$-ном уровне значимости. На следующем этапе были построены регрессионные модели случайных и фиксированных эффектов и проведены тесты спецификации, с целью выбора наиболее адекватной модели. Были проведены Wald test, Breush-Pagan test, Hausman test. Их результаты (для модели по всей выборке) приведены в таблице 4. 
Результаты тестов спецификации для общей модели

\begin{tabular}{|l|l|}
\hline \multicolumn{1}{|c|}{ Тест } & \multicolumn{1}{|c|}{ Статистики } \\
\hline Wald Test & $\begin{array}{l}\mathrm{F} \text { test that all } \mathrm{u}_{-} \mathrm{i}=0: \mathrm{F}(37, \quad 184)=5,06 \\
\text { Prob }>\mathrm{F}=0,0000\end{array}$ \\
\hline Breusch-Pagan Test & $\chi^{2}(1)=60,09$ Prob $>\chi^{2}=0,0000$ \\
\hline Hausman Test & $\chi 2(2)=21,79$ Prob $>\chi^{2}=0,0000$ \\
\hline
\end{tabular}

Результат теста Вальда говорит о том, что модель с фиксированными эффектами предпочтительнее обычной регрессионной модели.

Результат теста Бройша-Пагана говорит о том, что модель со случайными эффектами предпочтительнее сквозной регрессионной модели;

Результат теста Хаусмана позволяет прийти к заключению, что модель с фиксированными эффектами предпочтительнее модели со случайными эффектами. Данный результат ожидаем, поскольку мы рассматриваем одни и те же компании из года в год. Таким образом, именно модель с фиксированным эффектом позволяет адекватно описать имеющиеся данные. Аналогичные тесты для панельных моделей с включением даммипеременной кризисного периода позволили прийти к выводу о предпочтительности модели со случайными эффектами, что отражено в таблице 5. Что кажется вполне логичным, с учетом нестабильности кризисного периода. Кроме того, модель случайных эффектов (формула 2), учитывающая период кризиса, обладает наивысшим значением статистики Вальда (Wald chi), которое составило 302,65.

Таблица 5

Результаты тестов спецификации для модели кризисного периода

\begin{tabular}{|l|l|}
\hline \multicolumn{1}{|c|}{ Тест } & \multicolumn{1}{|c|}{ Статистики } \\
\hline Wald Test & $\begin{array}{l}\mathrm{F} \text { test that all } \mathrm{u} \mathrm{i}_{\mathrm{i}}=0: \mathrm{F}(37,184)=5,06 \\
\text { Prob }>\mathrm{F}=0,0000\end{array}$ \\
\hline Breusch-Pagan Test & $\chi^{2}(1)=82,88$ Prob $>\chi^{2}=0,0000$ \\
\hline Hausman Test & $\chi 2(2)=5,42$ Prob $>\chi 2=0,1437$ \\
\hline
\end{tabular}

Таким образом, итоговая модель для выборки на всем периоде выглядят следующим образом:

Таким образом, значимость влияния уровня раскрытия информации об интеллектуальном капитале на стоимость компании подтверждается.

\section{Заключение}

В рамках существующей системы экономики знаний особое значение приобретает своевременность и качество предоставленной компаниями информации. Причем более качественно раскрытие оказывается позитивным, как для внешних, так и для внутренних стейкхолдеров. Очень интересной, но и наиболее сложной, как с точки зрения адекватного предоставления, так и с точки зрения оценки, является информация об ИК, в силу свойств этого типа капитала. На данный момент не существует единой практики раскрытия информации об ИК. В научных кругах разрабатываются различные способы оценки раскрытия ИК среди компаний, но они не приводят к однозначным результатам.

В данной работе представлена оценка раскрытия информации об ИК компаний развивающихся стран (Бразилии, России, Китая, Южной Африки) с помощью индекса раскрытия. 
Непосредственные результаты описываемого исследования следующие:

- Были приведены базовые схемы структурирования интеллектуального капитала, а также основные методы его оценивания.

- Рассмотрены мотивы раскрытия информации об интеллектуальном капитале.

- Была проведена оценка интеллектуального капитала с помощью кумулятивного метода. При реализации использовался контент-анализ годовых отчетов компаний развивающихся стран (Бразилии, России, Китая, Южной Африки). Было выявлено увеличение уровня раскрытия информации об интеллектуальном капитале по годам. Наиболее раскрываемым типом капитал стал человеческий, наименее структурный (внутренний).

- Была построена регрессионная модель влияния раскрытия информации об интеллектуальном капитале на стоимость компаний стран развивающихся стран (Бразилии, России, Китая, Южной Африки) в период 2005-2010 годов и выявлена их существенная взаимосвязь. При разделении аналитического периода на докризисный и кризисный было выявлено, что в период нестабильности раскрытие дополнительной информации в большей мере влияет на стоимость компании, чем без выделения кризисного диапазона.

Проведенное исследование позволяет получить обобщенную картину раскрытия информации об интеллектуальном капитале в компаниях развивающихся стран (Бразилии, России, Китая, Южной Африки), а также показывает, что раскрытие подобной информации способствует росту стоимости компании, позволяя стейкхолдерам оценивать ее более адекватно.

Дальнейшее развитие данной тематики может лежать, во-первых, в усовершенствовании и усложнении проводимого контент-анализа в соответствии с методикой, рассмотренной в исследовании. Причем для снятия ограничений, связанных с недоступностью годовых отчетов, автор данной работы предложил бы использовать другие источники информации о компаниях. Например, источником информации могут стать прессрелизы, публикуемые компаниями на их официальных веб-сайтах.

Во-вторых, возможно усовершенствование процедуры формирования рейтинга, в виде перехода от подсчета количества упоминаний фраз к бинарным или иным системам учета для обеспечения сравнимости получаемых по разным компаниям результатов. Наконец, возможно рассмотрение влияния раскрытия информации об интеллектуальном капитале на затраты на капитал компаний и эффективность их деятельности.

\section{Список литературы}

1. Березинец И.В., Удовиченко О.М., Сысолятина Е.В. Оценка вклада интеллектуального капитала в создание ценности компании // Корпоративные финансы. 2010. № 3, т. 15. С. 522.

2. Abhayawansa, S. (2011), A methodology for investigating intellectual capital information in analyst reports , Journal of Intellectual Capital, 12(3) (2011) 446-476.

3. Abeysekera, I., Guthrie, J. (2005), An empirical investigation of annual reporting trends of intellectual capital in Sri Lanka, Critical Perspectives on Accounting, 16 (2005) 151-163.

4. Abdolmohammadi, M. (2005), Intellectual capital disclosure and market capitalization, Journal of Intellectual Capital, 6(3) (2005) 397-416.

5. An, Y., Davey, H., Eggleton, I. (2011), Towards a comprehensive theoretical framework for voluntary IC disclosure, Journal of Intellectual Capital, 12(4) (2011) 571-585.

6. Anam, O.A., Fatima, A.H., Majdi, A.R.H. (2011), Effects of intellectual capital information disclosed in annual reports on market capitalization: Evidence from Bursa Malaysia, Journal of Human Resource Costing \&Accounting, 15(2) (2011) 85-101.

7. Bayburina, E.R., Golovko, T.V. (2009), Design of Sustainable Development: Intellectual Value of Large BRIC Companies and Factors of their Growth, Electronic Journal of 
Knowledge Management, 7(5) (2009) 535-558.

8. Beaulieu, P., Williams, S., Wright, M. (2002), Intellectual Capital Disclosures in Swedish Annual Reports, World Congress on Intellectual Capital Readings, (2002) 135-156.

9. Branco, M.C., Delgado, C., Sousa, M. (2010), An analyses of intellectual capital disclosure by Portuguese companies, EuroMed Journal of Business, 5(3) (2010) 258-278.

10. Brennan, N., Connell, B. (2000), Intellectual capital: current issues and policy implications, Journal of intellectual capital, 1(3) (2000) 206-240.

11. Bontis, N. (2003), Intellectual capital disclosure in Canadian corporations, Journal of Human Resource Costing \& Accounting, 7(1/2) (2003) 920.

12. Bozzolan, S., O’Regan, P., Ricceri, F. (2006), Intellectual capital disclosure (ICD). A comparison of Italy and the UK, Journal of Human Resource Costing and Accounting, 10(2) (2006) 92-113.

13. Chiung-Ju, L., Ming-Li, Y. (2005), The Value-Relevance of Financial and Nonfinancial Information- Evidence from Taiwans's Information Electronics Industry, Review of Quantitative Finance and Accounting, 24 (2005) 135-157.

14. Citron, D., Holden, J., Selim, G., Oehlche, F. (2005), Do voluntary intellectual capital disclosure provide information about firm's intangible assets? 9th Financial Reporting and Business Communication Conference, Cardiff Business School, London, July (2005).

15. Edvinsson, L., Malone, M. (1997), Intellectual Capital: The Proven Way to Establish Your Company's Real Value by Measuring Its Hidden Brain Power. Piatkus, London.

16. Goh, P., Lim, K. (2004), Disclosing intellectual capital in company annual reports: Evidence from Malaysia, Journal of Intellectual Capital, 5(3) (2004) 500-510.

17. Guthrie, J., Petty, R. (2000), Intellectual capital: Australian annual reporting practices, Journal of Intellectual Capital, 1(3) (2000) 241-251.

18. Guthrie, J., Petty, R., Ricceri, F. (2006), The voluntary reporting of intellectual capital. Comparing evidence from Hong Kong and Australia, Journal of Intellectual Capital, 7(2) (2006) 254-271.

19. Husin, M.N., Hooper, K., Olesen, K. (2012), Analysis of intellectual capital disclosure - an illustrative example, Journal of Intellectual Capital, 13(2) (2012) 196-220.

20. Kamath, B. (2008), Intellectual capital disclosure in India: content analysis of "Tech" firms, Journal of Human Resource Costing \&Accounting, 12(3) (2008) 213-224.

21. Kaplan, R., Norton, D. (1992), The balanced scorecard- measures that drives performance. /Harvard Business Review, 70(1) (1992) 71-99.

22. Klein, D., Prusak, L. (1994), Characterizing intellectual capital, Center for Business Innovation, Ernst \& Young LLP Working Paper, New York.

23. Miller, J., Whiting, R.H. (2008), Voluntary disclosure of intellectual capital in New Zealand annual reports and the "hidden value", Journal of Human Resource Costing and Accounting, 12(1) (2008) 2650.

24. Oliveras, E., Gowthorpe, C., Kasperskaya, Y., Perramon, J. (2008), Reporting intellectual capital in Spain, Corporate Communications: An International Journal, 13(2) (2008) 16-21.

25. Orens, R., Aerts, W., Lybaert, N. (2009), Intellectual capital disclosure, cost of finance and firm value, Management Decision, 47(10) (2009) 1536-1554.

26. Petty, R., Cuganesan, S. (2005), Voluntary disclosure of intellectual capital by Hong Kong companies: examining size, industry and growth effects over time, Australian Accounting Review, 15(2) (2005) 40-50.

27. Puntillo, P. (2009), Intellectual Capital and business performance. Evidence from Italian banking industry, EJournal of corporate finance 4(12) (2009) 96-115.

28. Rodov, I., Leliaert, P. (2002), FIMIAM: financial method of intangible assets measurement, Journal of Intellectual Capital, .3(3) (2002) 323-336.

29. Singh, I., Zahn, J. (2008), Determinants of intellectual capital disclosure in prospectuses of initial public offerings, Accounting and Business Research, 38(5) (2008) 409-431.

30. Sveiby, K. Knowledge Associates официальный сайт. [Электронный ресypc]. URL: 
www.sveiby.com.

31. Sveiby, K. (1997), The intangible asset monitor, Journal of Human Resource Costing and Accounting, 1 (1997) 73-97.

32. Williams, P., Naumann, E. (2011), Customer satisfaction and business performance: a firmlevel analysis, Journal of Services Marketing, 25(1) (2011) 20-32. 


\section{Приложение}

Таблица А

Методы измерения интеллектуального капитала

\begin{tabular}{|c|c|}
\hline Название метода & Описание метода \\
\hline $\begin{array}{l}\text { - Методы прямого } \\
\text { измерения } \\
\text { интеллектуального } \\
\text { капитала (Direct } \\
\text { intellectual capital } \\
\text { methods - DIC) }\end{array}$ & $\begin{array}{l}\text { Методы состоят в денежной оценке конкретных компонентов интеллектуального капитала. } \\
\text { Применение данного метода представляется затруднительным для элементов интеллектуального капитала, не } \\
\text { имеющих материальной субстанции и возможности быть проданными или купленными (Березинец и др. 2010). }\end{array}$ \\
\hline $\begin{array}{c}\text { • Методы рыночной } \\
\text { капитализации (Market } \\
\text { Capitalization Methods- } \\
\text { MCM) }\end{array}$ & $\begin{array}{l}\text { Методы предполагают вычисление разности между рыночной капитализацией компании и балансовой стоимостью } \\
\text { ее собственного капитала, которая рассматривается как показатель стоимости интеллектуального капитала компании. } \\
\text { Ограничением по применению этих методов является необходимость исследования исключительно котируемых } \\
\text { компаний. } \\
\text { Инвесторы могуг быть не полностью осведомлены обо всех характеристиках компании, которые могли бы повлиять } \\
\text { на их оценку ее стоимости, выраженную рыночной капитализацией (Березинец и др. 2010). }\end{array}$ \\
\hline $\begin{array}{c}\text { - Методы отдачи на } \\
\text { aктивы (Return on Assets } \\
\text { Methods-ROA) }\end{array}$ & $\begin{array}{l}\text { В рамках данных методов превышение доходности активов компании над средним уровнем по отрасли считается } \\
\text { последствием наличия у компании специфичного интеллектуального капитала. }\end{array}$ \\
\hline $\begin{array}{l}\text { - Кумулятивные } \\
\text { методы (Scorecards' } \\
\text { Methods-SCM) }\end{array}$ & $\begin{array}{l}\text { При применении данных методов рассчитываются различные индексы в соответствие с выделенными компонентами } \\
\text { интеллектуального капитала. } \\
\text { Данная группа методов представляет собой неденежную оценку интеллектуального капитала, что является } \\
\text { преимуществом, поскольку не вызывает необходимость опираться на прокси-переменные из бухгалтерских отчетов. } \\
\text { В целом, они позволяют дать довольно полную оценку интеллектуального капитала компании, однако, зачастую } \\
\text { являются довольно трудоемкими с точки зрения реализации. } \\
\text { Ограничением применения кумулятивного метода может стать недостаточное развитие практик раскрытия } \\
\text { информации в развивающихся странах в целом. В особенности потому, что раскрытие информации об ИК является } \\
\text { добровольным. }\end{array}$ \\
\hline
\end{tabular}


Таблица В

Теории раскрытия информации об интеллектуальном капитале

\begin{tabular}{|c|c|}
\hline Название теории & Описание теории \\
\hline - Агентская теория & $\begin{array}{l}\text { Интеллектуальный капитал считается одним из значимых факторов создания стоимости компании в современных } \\
\text { условиях (Sveiby, 1997; An, Davey, 2011). Добровольное раскрытие дополнительной информации об интеллектуальном } \\
\text { капитале позволяет уменьшить асимметрию информации между принципалом (акционерами) и агентом } \\
\text { (менеджментом компании) и, соответственно, сократить возникающие в связи с асимметрией издержки. За счет } \\
\text { раскрытия информации об ИК, возможно снижение стимулов для оппортунистического поведения менеджеров } \\
\text { благодаря появлению больших возможностей для мониторинга деятельности компании. Согласно исследованию } \\
\text { (Singh, Zahn, 2008), добровольное раскрытие информации об ИК снижает затраты на капитал компании, так как } \\
\text { инвесторы и кредиторы получают больше информации о механизме формирования стоимости. }\end{array}$ \\
\hline - Теория стейкхолдеров & $\begin{array}{l}\text { Согласно данной теории, компания является частью крупной социальной системы, в которой она осуществляет свою } \\
\text { деятельность, и должна соотносить собственные интересы с интересами других агентов (стейкхолдеров, или } \\
\text { заинтересованных лиц) в системе. К таким стейкхолдерам относится государство, инвесторы, кредиторы, работники } \\
\text { компании и др. Аналогично предыдущему случаю, спрос на информацию об ИК, важную для создания стоимости } \\
\text { компании, со стороны стейкхолдеров повышается. Современные исследования, в которых исследуется данный мотив } \\
\text { раскрытия информации об ИК, позволяют прийти к заключению, что уровень раскрытия не отвечает потребностям } \\
\text { стейкхолдеров в полной мере (Guthrie et al., 2006; Miller, Whiting, 2008). }\end{array}$ \\
\hline - Сигнальная теория & $\begin{array}{l}\text { Сигнальная теория предполагает, что компании могут информировать рынок о своих преимуществах относительно } \\
\text { других, что позволит стейкхолдерам оценивать ее верно и принимать относительно нее благоприятные решения. } \\
\text { Например, это может позволить компании снизить затраты на капитал из-за большей привлекательности для } \\
\text { инвесторов. Помимо снижения затрат на капитал, подобные положительные сигналы о качестве могут } \\
\text { способствовать формированию благоприятной репутации, привлечению потенциальных инвесторов, сокращению } \\
\text { волатильности акций, в целом улучшению отношений со стейкхолдерами (Singh, Zahn, 2008). }\end{array}$ \\
\hline - Теория легитимности & $\begin{array}{l}\text { Данная теория основывается на том, что компания и общество в целом заключают некий «социальный контракт». } \\
\text { Таким образом, компания продолжает деятельность только, если удовлетворяет ожиданиям и нормам, принятым в } \\
\text { этом обществе. Иными словами, если она является легитимной. Добровольно раскрытая информация об ИК может } \\
\text { свидетельствовать о легитимности компании (Abeysekera, Guthrie, 2005; Guthrie et al., 2006; Petty, Cuganesan, 2005; Miller, } \\
\text { Whiting, 2008). }\end{array}$ \\
\hline
\end{tabular}

